\title{
Aspergillus flavus Infection and Aflatoxin Accumulation in Resistant and Susceptible Maize Hybrids
}

\author{
G. L. Windham and W. P. Williams, USDA-ARS, Crop Science Research Laboratory, P.O. Box 5367, Mississippi \\ State, MS 39762
}

\begin{abstract}
Windham, G. L., and Williams, W. P. 1998. Aspergillus flavus infection and aflatoxin accumulation in resistant and susceptible maize hybrids. Plant Dis. 82:281-284.

Field studies were conducted for 2 years in Mississippi to monitor maize kernel infection and aflatoxin accumulation caused by Aspergillus flavus at various times during the growing season. Hybrids resistant and susceptible to A. flavus were compared to determine temporal differences in infection and aflatoxin levels. The resistant hybrids tested were Mo18W $\times \mathrm{Mp} 313 \mathrm{E}, \mathrm{Mp} 420 \times$ Tx601, and SC54 × SC76; and the susceptible hybrids tested were GA209 $\times$ Mp339, Mp307 × Mp428, and Mp68:616 $\times$ SC212M. The top ear of each plant was inoculated with a suspension containing A. flavus conidia at 7 days after midsilk (50\% of the plants in a plot had silks emerged) using the side needle technique. Inoculated ears were harvested 35, 42, 49, 56, and 63 days after midsilk to determine kernel infection by A. flavus and aflatoxin contamination. Differences in aflatoxin levels between resistant and susceptible hybrids occurred in all harvest dates. However, significant differences between resistant and susceptible hybrids for kernel infection were not observed until 42 days after midsilk. Differences between resistant and susceptible hybrids occurred for kernel infection and aflatoxin concentrations 49, 56, and 63 days after midsilk. Incidence of kernel infection ( $8.1 \%$ for GA209 $\times$ Mp339) was the highest 49 days after midsilk, and aflatoxin concentrations $(510 \mathrm{ng} / \mathrm{g}$ for Mp307 $\times \mathrm{Mp} 428)$ were the highest 63 days after midsilk. Maximum differences between resistant and susceptible hybrids for aflatoxin levels were observed 63 days after midsilk. Two of the resistant hybrids, Mo18W $\times$ Mp313E and Mp420 × Tx601, had significantly less aflatoxin than the three susceptible hybrids 63 days after midsilk.
\end{abstract}

Additional keywords: corn, mycotoxin, resistance, Zea mays

Infection of maize kernels by Aspergillus flavus and subsequent accumulation of aflatoxin is a chronic economic and health safety problem in the southeastern United States and can be a problem in the Corn Belt $(2-4,7-9,17,21)$. Aflatoxins are some of the most potent carcinogens produced in nature. Aflatoxin $\mathrm{B}_{1}$ is the most commonly found aflatoxin in maize and is also the most potent. This aflatoxin has been the subject of numerous toxicological studies (3). The United States Food and Drug Administration has a tolerance of $20 \mathrm{ng} / \mathrm{g}$ for aflatoxin $B_{1}$ in maize (3). Grain that exceeds this level cannot be shipped through

Corresponding author: G. L. Windham

E-mail: gwindham@dorman.msstate.edu

Contribution of the USDA-ARS in cooperation with the Mississippi Agricultural and Forestry Experiment Station, Mississippi State 39762.

Accepted for publication 3 December 1997.

Publication no. D-1998-0109-01R

This article is in the public domain and not copyrightable. It may be freely reprinted with customary crediting of the source. The American Phytopathological Society, 1998. interstate commerce. Many countries have a tolerance of $10 \mathrm{ng} / \mathrm{g}$ in food supplies, while several countries have a zero tolerance for aflatoxin contamination (3).

Much information on A. flavus infection of maize and subsequent aflatoxin contamination has been published over the last 20 years. Several factors associated with increased aflatoxin formation in maize are drought stress $(2,11)$, high temperatures $(11)$, and insects $(9,10)$. Studies have been conducted to determine the time and location of $A$. flavus infection in maize $(7,12,14,18-20)$. Payne et al. (12) followed the rate of aflatoxin accumulation in ears of a susceptible maize hybrid. Aflatoxin appeared 1 week after inoculation and generally peaked 7 to 9 weeks after inoculation. No information on the temporal changes in A. flavus infection and the initiation of aflatoxin production in resistant maize compared with susceptible maize is available. Information on the timing of kernel infection and aflatoxin accumulation is needed to help researchers determine when to harvest maize genotypes to accurately determine levels of resistance. Field studies were conducted 2 years to monitor kernel infection and aflatoxin accumulation in hybrids resistant and susceptible to $A$. flavus to determine when maximum differences occurred.

\section{MATERIALS AND METHODS}

Three resistant hybrids (Mo18W $\times$ Mp313E, Mp420 × Tx601, and SC54 × SC76) and three susceptible hybrids $($ GA209 $\times$ Mp339, Mp307 $\times$ Mp428, and Mp68:616 $\times$ SC212M) were used in this study based on performance in other studies $(1,14,22)$. These hybrids were grown at the Plant Science Farm, Mississippi State, Mississippi, in a randomized complete block design with six replications in 1994 and 1995. Planting dates were 14 April 1994 and 7 April 1995. Single-row, 5.1-m plots spaced $0.96 \mathrm{~m}$ apart were thinned to 20 plants per plot. Plots received supplemental irrigation during each growing season to limit drought stress.

A. flavus isolate NRRL 3357, which is known to produce aflatoxin in maize grain (13), was used as inoculum both years. Inoculum was increased on sterile maize cob grits in 500-ml flasks, each containing $50 \mathrm{~g}$ of grits and $100 \mathrm{ml}$ of $\mathrm{H}_{2} \mathrm{O}$, and incubated at $28^{\circ} \mathrm{C}$. Conidia were washed from the grits using sterile distilled water containing 20 drops of Tween 20 per liter and filtered through four layers of sterile cheesecloth. The concentration of conidia was determined with a hemacytometer and adjusted with sterile distilled water to $9 \times$ $10^{7}$ conidia per ml. Inoculum not immediately used was refrigerated at $4^{\circ} \mathrm{C}$. Hybrids were inoculated 7 days after midsilk $(50 \%$ of the plants in the plots had silks emerged) using the side needle technique (22). The top ear of each plant was inoculated with a 3.4-ml suspension containing 3 $\times 10^{8}$ A. flavus conidia.

Inoculated ears were harvested 35,42 , 49, 56, and 63 days after midsilk. Grain moisture was measured using a DickeyJohn Grain Moisture Tester (Auburn, IL). Ears were then dried at $38^{\circ} \mathrm{C}$ for 7 days and machine shelled. Grain samples from each row were poured into a sample splitter twice to mix the grain. Half of the grain was used for aflatoxin analyses, and the other half was used for determination of kernel infection. Grain samples used in aflatoxin analyses were ground using a Romer mill (Union, MO). Aflatoxin contamination in 50-g subsamples from each 
plot was determined using the Vicam Aflatest (Watertown, MA). This procedure can detect aflatoxins $\left(B_{1}, B_{2}, G_{1}, G_{2}\right)$ at concentrations as low as $2 \mathrm{ng} / \mathrm{g}$.

Kernels evaluated for A. flavus infection were surface sterilized by dipping momentarily (5s) in $70 \%$ ethanol, soaking for $3 \mathrm{~min}$ in $1.5 \% \mathrm{NaOCl}$, and rinsing in sterile distilled water. The kernels were placed in $100-\mathrm{mm}$ petri dishes (13 kernels per dish, 390 kernels per plot) on Czapek solution agar amended with $7.5 \% \mathrm{NaCl}$ to restrict growth of other fungi and bacteria. After 7 days at $28^{\circ} \mathrm{C}$, kernels were examined for A. flavus growth.

Data were subjected to analysis of variance. Since there was no genotype by year interaction for kernel infection or aflatoxin accumulation, data from both years were combined for further analyses and for presentation. Means were compared by the least significant difference test (LSD) at $P$ $=0.05$. Means of resistant and susceptible hybrids for kernel infection and aflatoxin accumulation were compared using orthogonal contrasts.

\section{RESULTS}

Differences $(P=0.05)$ in $A$. flavus kernel infection were not found until the second harvest date (42 days after midsilk) (Table 1). Two of the resistant hybrids, Mo18W $\times$ Mp313E and Mp420 × Tx601, had significantly lower incidence of kernel infection than did Ga209 $\times$ Mp339 and Mp307 × Mp428. At 49 days after midsilk, all of the resistant hybrids had significantly $(P=0.05)$ less kernel infection than the susceptible hybrids. Mo18W $\times$ Mp313E and Mp420 × Tx601 had the lowest levels of kernel infection at the last two harvest dates. Incidence of kernel infection for two susceptible hybrids (GA209 × Mp339 and Mp307 $\times$ Mp428) peaked 49 days after midsilk. Kernel infection in the other susceptible hybrid (Mp68:616 × SC212M) was the greatest 56 days after midsilk.

When the means of resistant and susceptible hybrids were compared using orthogonal contrasts, no differences were found for kernel infection on the first harvest date (Fig. 1A). However, significant differences $(P=0.05)$ between resistant and susceptible hybrids were observed at the last four harvest dates. Maximum differences in kernel infection between resistant and susceptible hybrids were found 49 days after midsilk (Fig. 1A).

Aflatoxin levels differed significantly $(P$ $=0.05)$ between resistant and susceptible hybrids at the first harvest date (35 days after midsilk) (Table 2). All of the resistant hybrids had lower aflatoxin concentrations than two of the susceptible hybrids $(\mathrm{GA} 209 \times \mathrm{Mp} 339$ and Mp307 × Mp428). Aflatoxin concentrations in Mp68:616 $\times$ SC212M at the first harvest were comparable to those in the three resistant hybrids. Generally, for the other harvest dates, aflatoxin accumulated at a much slower
Table 1. Aspergillus flavus kernel infection (\%) of resistant and susceptible maize hybrids at five harvest dates

\begin{tabular}{lccccc}
\hline & \multicolumn{5}{c}{ Days after midsilk } \\
\cline { 2 - 5 } Hybrid & $\mathbf{3 5}$ & $\mathbf{4 2}$ & $\mathbf{4 9}$ & $\mathbf{5 6}$ & $\mathbf{6 3}$ \\
\hline Resistant & & & & \\
Mo18W $\times$ Mp313E & $3.8^{\mathrm{a}}$ & 3.2 & 2.9 & 2.9 & 3.2 \\
Mp420 × Tx601 & 3.9 & 2.1 & 3.2 & 2.2 & 2.7 \\
SC54 $\times$ SC76 & 5.0 & 4.3 & 3.7 & 5.7 & 6.6 \\
Susceptible & & & & 5.7 \\
GA209 $\times$ Mp339 & 3.5 & 6.4 & 8.1 & 6.1 & 5.8 \\
Mp307 $\times$ Mp428 & 5.4 & 6.3 & 7.3 & 8.0 & 7.5 \\
Mp68:616 $\times$ SC212M & 3.0 & 4.8 & 7.7 & 2.0 & 2.1 \\
LSD $(P=0.05)$ & $\mathrm{NS}$ & 2.8 & 2.7 & & \\
\hline
\end{tabular}

${ }^{a}$ Data are mean values of 12 replicates.

${ }^{\mathrm{b}}$ No significant difference among hybrids.
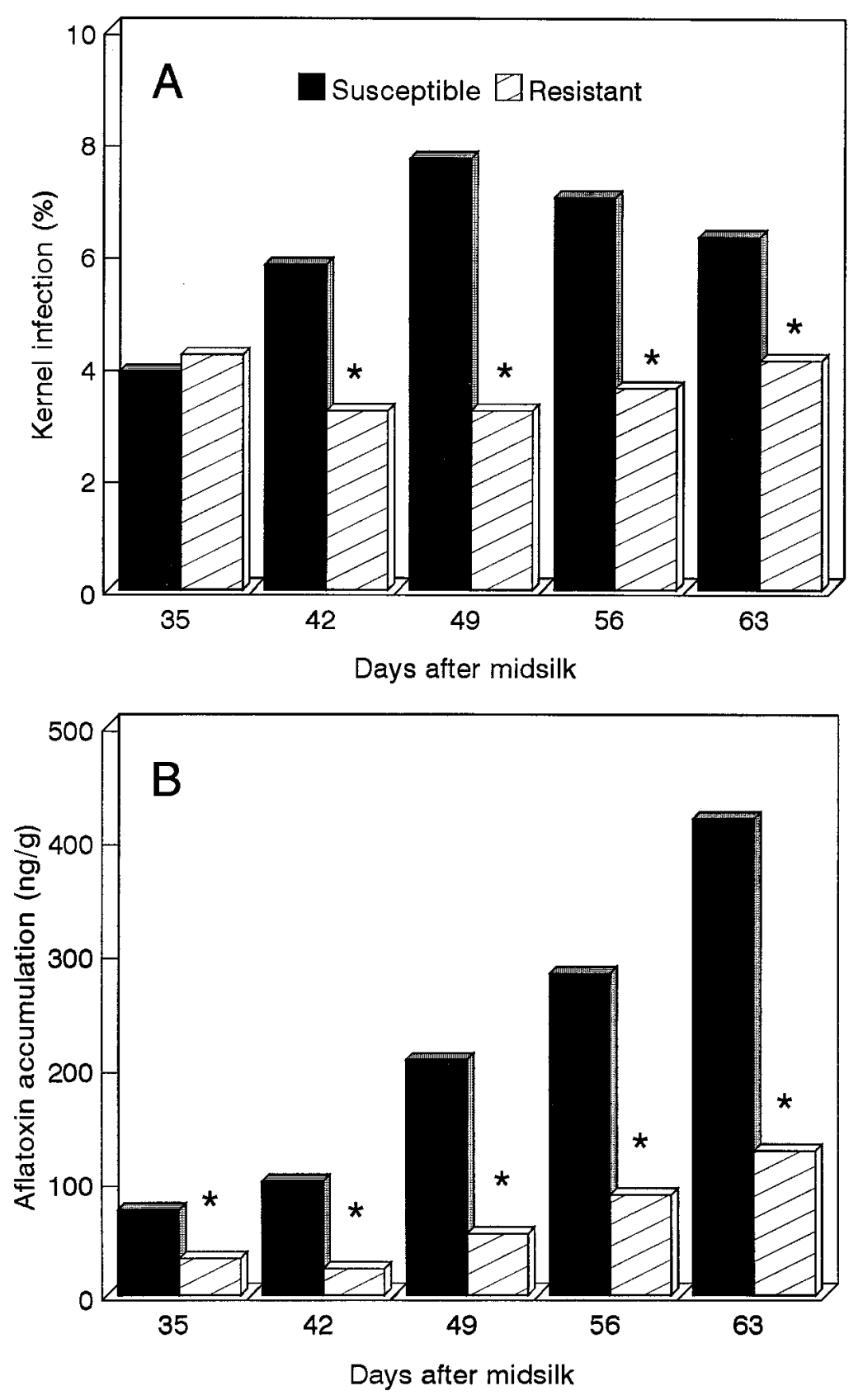

Fig. 1. Kernel infection (A) and aflatoxin accumulation (B) in resistant and susceptible maize hybrids at five harvest dates. Each bar represents the mean of three genotypes. An asterisk indicates a significant difference $(P=0.05)$ in the orthogonal contrast: resistant vs. susceptible. 
rate in the resistant hybrids than in the susceptible hybrids. By the last harvest date, the resistant hybrid $(\mathrm{Mo18W} \times$ $\mathrm{Mp} 313 \mathrm{E}$ ) had the lowest concentration of aflatoxin $(93 \mathrm{ng} / \mathrm{g})$, and the susceptible hybrid (Mp307 × Mp428) had the highest $(510 \mathrm{ng} / \mathrm{g})$. For most harvest dates, the resistant hybrids Mo18W $\times \mathrm{Mp} 313 \mathrm{E}$ and Mp420 × Tx601 had significantly lower aflatoxin concentrations than did the susceptible GA209 × Mp339 and Mp307 × Mp428 hybrids.

When data for the three resistant hybrids were combined and data for the three susceptible hybrids were combined, differences $(P=0.05)$ in aflatoxin concentrations between the two groups of hybrids were noted at all harvest dates (Fig. 1B). Aflatoxin accumulation was always higher in the susceptible group of hybrids. Maximum differences in aflatoxin concentrations were observed at the last harvest date (63 days after midsilk).

Kernel infection and aflatoxin concentrations were each negatively correlated $(P$ $=0.0001)$ with grain moisture. Over time, as the maize dried down, kernel infection and aflatoxin levels increased. Moisture levels in the resistant hybrids were higher than moisture levels in susceptible hybrids at the early harvest dates (Fig. 2). As the season progressed, moisture levels in the two groups began to converge, reaching the

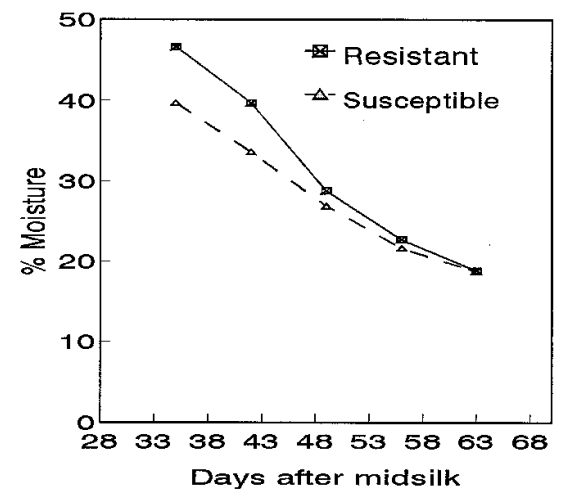

Fig. 2. Grain moisture for susceptible (Mp307 $\times$ Mp428, GA209 × Mp339, and Mp68:616 × SC212M) and resistant $(\mathrm{Mo} 18 \mathrm{~W} \times \mathrm{Mp313E}$, SC54 × SC76, and Mp420 × Tx601) maize hybrids at five harvest dates after midsilk.

Table 2. Aflatoxin accumulation (ng/g) in the grain of resistant and susceptible maize hybrids infected with Aspergillus flavus

\begin{tabular}{llrrrr}
\hline & \multicolumn{5}{c}{ Days after midsilk } \\
\cline { 2 - 6 } Hybrid & $\mathbf{3 5}$ & $\mathbf{4 2}$ & $\mathbf{4 9}$ & $\mathbf{5 6}$ & $\mathbf{6 3}$ \\
\hline Resistant & & & & & \\
Mo18W $\times$ Mp313E & $34^{\mathrm{a}}$ & 33 & 65 & 53 & 93 \\
Mp420 $\times$ Tx601 & 26 & 14 & 49 & 72 & 104 \\
SC54 $\times$ SC76 & 36 & 24 & 48 & 139 & 186 \\
Susceptible & & & & & \\
GA209 $\times$ Mp339 & 97 & 94 & 196 & 329 & 379 \\
Mp307 $\times$ Mp428 & 89 & 134 & 290 & 183 & 510 \\
Mp68:616 $\times$ SC212M & 39 & 74 & 136 & 339 & 369 \\
LSD $(P=0.05)$ & 42 & 86 & 128 & 162 & 261 \\
\hline
\end{tabular}

${ }^{\mathrm{a}}$ Data are mean values of 12 replicates. same levels of moisture 63 days after midsilk.

\section{DISCUSSION}

Aflatoxin accumulation in susceptible maize genotypes has been monitored in previous studies $(7,12,14,18,20)$. Thompson et al. (18) found aflatoxin in maize kernels 2 days postinoculation, and aflatoxin concentrations peaked 9 days postinoculation. In another study (7), aflatoxin concentrations peaked 30 days after inoculation. Others have found that aflatoxin levels increased linearly throughout the growing season and peaked near physiological maturity $(12,20)$. Our findings agree more with the latter studies with a linear increase in aflatoxin accumulation. In our study, aflatoxin levels for all resislast harvest. Payne et al. (12) reported a significant drop in aflatoxin levels close to their last harvest dates. This drop in aflatoxin concentration did not occur in our study.

Two of the hybrids did not exhibit the same level of resistance or susceptibility to A. flavus as reported in other studies. The resistant hybrid SC54 $\times$ SC76 had low levels of A. flavus kernel infection when inoculated with a pinbar, which is a severe inoculation technique (22). In our study, however, the incidence of kernel infection in SC54 × SC76 63 days after midsilk was comparable to that of the three susceptible hybrids. Also, the susceptible hybrid Mp68:616 × SC212M had less kernel infection in our study than that reported by Zummo and Scott (22). After inoculation with A. flavus using the side needle technique, kernel infection of Mp68:616 $\times$ SC212M in that study was over $20 \%$. In our study, at the initial harvest date, this hybrid had numerically the lowest level of infection of any of the hybrids; however, after the second harvest date, the levels were indicative of the expected susceptibility. The resistant hybrid Mp420 × Tx601 demonstrated high levels of resistance in our study and also in other studies $(1,14,22)$.

Few characteristics that cause certain infection and limit subsequent aflatoxin tant and susceptible hybrids peaked at the hybrids to be resistant to A. flavus kernel contamination have been documented $(5,6)$. Kernel moisture of the hybrids was monitored to determine if moisture levels played a role in resistance. Different rates of drying by resistant and susceptible hybrids apparently contributed little to the differences in kernel infection and aflatoxin levels we observed. At the first harvest dates, when differences in moisture were the greatest, there were no significant differences in kernel infection. At the last harvest date, when moisture levels were the same for resistant and susceptible hybrids, the differences in aflatoxin contamination were the greatest.

Researchers have conducted numerous studies in efforts to identify field resistance to A. flavus $(1,13,15,16)$. Resistance has been selected using kernel infection and also by monitoring aflatoxin concentrations, or by selecting for resistance by evaluating for both parameters. Progress has been made in identifying genotypes with resistance to kernel infection $(15,16)$. However, resistant material still allowed the accumulation of aflatoxin as determined in our study. Aflatoxin concentrations found in all of the resistant hybrids on the first harvest date were above the FDA tolerance level $(20 \mathrm{ng} / \mathrm{g})$. The only hybrid with an aflatoxin level below the tolerance level was Mp420 × Tx601 42 days after midsilk. In general, aflatoxin concentrations tend to be higher in ears mechanically inoculated with A. flavus than in ears naturally infected by A. flavus.

Temporal aflatoxin accumulation in resistant hybrids was similar to the pattern seen in susceptible hybrids; however, aflatoxin accumulation was at a much lower level in the resistant hybrids. Differences between the susceptible and resistant hybrids in kernel infection and aflatoxin contamination were detected at the early harvest dates and would allow for early selection of resistance in certain cases. However, the maximum differences in aflatoxin contamination were not found until later in the test. Kernel infection peaked 49 days after midsilk; whereas aflatoxin levels did not peak until the last harvest date. Since measuring aflatoxin concentrations is more definitive than kernel infection in selecting for resistance, field plots should be harvested near 63 days after midsilk.

\section{LITERATURE CITED}

1. Campbell, K. W., and White, D. G. 1995 Evaluation of corn genotypes for resistance to Aspergillus ear rot, kernel infection, and aflatoxin production. Plant Dis. 79:10391045

2. Diener, U. L. 1989. Preharvest aflatoxin contamination of peanuts, corn, and cottonseed A review. Biodeterioration Res. 2:217-244.

3. Gourama, H., and Bullerman, L. B. 1995. Aspergillus flavus and Aspergillus parasiticus: Aflatoxigenic fungi of concern in foods and feeds: A review. J. Food Prot. 58:1395-1404.

4. Gray, F. A., Faw, W. F., and Boutwell, J. L. 1982. The 1977 corn-aflatoxin epiphytotic in 
Alabama. Plant Dis. 66:221-222.

5. Guo, B. Z., Russin, J. S., Cleveland, T. E., Brown, R. L., and Damann, K. E. Evidence for cutinase production by Aspergillus flavus and its possible role in infection of corn kernels. Phytopathology 86:824-829.

6. Guo, B. Z., Russin, J. S., Cleveland, T. E., Brown, R. L., and Widstrom, N. W. 1995. Wax and cutin layers in maize kernels associated with resistance to aflatoxin production by Aspergillus flavus. J. Food Prot. 58:296300.

7. Lillehoj, E. B., Kwolek, W. F., Vandegraft, E. E., Zuber, M. S., Calvert, O. H., Widstrom, N., Futrell, M. C., and Bockholt, A. J. 1975. Aflatoxin production in Aspergillus flavus inoculated ears of corn grown at diverse locations. Crop Sci. 15:267-270.

8. Lillehoj, E. B., Kwolek, W. F., Zuber, M. S., Bockholt, A. J., Calvert, O. H., Findley, R., Guthrie, W. D., Horner, E. S., Josephson, L. M., King, S., Manwiller, A., Sauer, D. B., Thompson, D., Turner, M., and Widstrom, N. W. 1980. Aflatoxin in corn before harvest: Interaction of hybrids and locations. Crop Sci. 20:731-734.

9. Lillehoj, E. B., Kwolek, W. F., Zuber, M. S., Horner, E. S., Widstrom, N. W., Guthrie, W. D., Turner, M., Sauer, D. B., Findley, W. R.,
Manwiller, A., and Josephson, L. M. 1980. Variation between hybrids developed for specific regions but grown at diverse locations. Plant Soil 54:469-475.

10. McMillian, W. W., Wilson, D. M., and Widstrom, N. W. 1985. Aflatoxin contamination of preharvest corn in Georgia: A six-year study of insect damage and visible Aspergillus flavus. J. Environ. Qual. 14:200-202.

11. Payne, G. A. 1992. Aflatoxin in maize. Crit. Rev. Plant Sci. 10:423-440.

12. Payne, G. A., Hagler, W. M., Jr., and Adkins, C. R. 1988. Aflatoxin accumulation in inoculated ears of field-grown maize. Plant Dis. 72:422-424.

13. Scott, G. E., and Zummo, N. 1988. Sources of resistance in maize to kernel infection by Aspergillus flavus in the field. Crop Sci. 28:504507.

14. Scott, G. E., and Zummo, N. 1990. Preharvest kernel infection by Aspergillus flavus for resistant and susceptible maize hybrids. Crop Sci. 30:381-383.

15. Scott, G. E., and Zummo, N. 1990. Registration of Mp313E parental line of maize. Crop Sci. 30:1378.

16. Scott, G. E., and Zummo, N. 1992. Registration of Mp420 germplasm line of maize. Crop Sci. 32:1296.
17. Shane, S. M. 1994. Economic issues associ ated with aflatoxins. Pages 513-527 in: The Toxicology of Aflatoxins: Human Health, Veterinary, and Agricultural Significance. D L. Eaton and J. D. Groopman, eds. Academic Press, New York.

18. Thompson, D. L., Payne, G. A., Lillehoj, E. B., and Zuber, M. S. 1983. Early appearance of aflatoxin in developing corn kernels after inoculation with Aspergillus flavus. Plant Dis. 67:1321-1322.

19. Widstrom, N. W., Wilson, D. M., and McMillian, W. W. 1981. Aflatoxin contamination of preharvest corn as influenced by timing and method of inoculation. Appl. Environ. Microbiol. 42:249-251.

20. Widstrom, N. W., Wilson, D. M., and McMillian, W. W. 1986. Differentiation of maize genotypes for aflatoxin concentration in developing kernels. Crop Sci. 26:935-937.

21. Zuber, M. S., Calvert, O. H., Lillehoj, E. B., and Kwolek, W. F. 1976. Preharvest development of aflatoxin $\mathrm{B}_{1}$ in corn in the United States. Phytopathology 66:1120-1121.

22. Zummo, N., and Scott, G. E. 1989. Evaluation of field inoculation techniques for screening maize genotypes against kernel infection by Aspergillus flavus in Mississippi. Plant Dis. 73:313-316. 